\title{
A Proclamação da República e a Cidadania
}

\author{
José Carlos Vargens Tambasco \\ Doutor em História, pela Universidade Federal \\ Fluminense, Membro do Instituto Histórico e Geográfico de \\ Vassouras, Acadêmico da Academia de Letras de Vassouras, \\ Pesquisador independente \\ jcvartameuol.com.br
}

Resumo: Procuramos enfatizar, no presente estudo, a ausência do sentimento de cidadania no povo carioca - e por extensão, no brasileiro - quando da Proclamação da República.Procuramos mostrar que a Repíblica, entre nós, surgiu de um movimento de pura insatisfação militar, não tendo sido em nada influenciada pela Abolição da Escravatura,e muito menos pela Questão Religiosa. Contudo, esta última estava a indicar que, para tocar nos sentimentos de um povo, é necessário ter-se sensibilidade, o que a República não teve, conduzindo-se àquele terrivel genocídio, que foi a Guerra de Canudos. Para estas reflexões,utilizamo-nos de manifestações literárias da época, bem como d e alguns documentos produzidos por participes e testemunhas oculares dos fatos, durante aquela jornada.

Palavras-chave: Proclamação da República. Cidadania. Guerra de Canudos. Positivismo.

\section{La Proclammation de la Republique et la Citoyennetée}

Resumé: Nous avons chercé à charactériser l'absence du sentiment de citoyennetée parmi le peuple de la ville du Rio de Janeiro - et par extension, au Bèésil - au instant de la Proclamation de la Republique. Pour analyser cette qurstion, nous avons pris, soit de pages de la literature brèsilienne de l'époque, soit de témoignages de participants civiles de catte journée La Guerra de Canudos est évoquée comme consequence de la Quesrion Religieuse.

Mots-clé: Proclamation de la République. Citoyennetée. La Guerre en 'Canudos'. Positivisme. 


\section{Monarquia, ou República Militarista?}

Machado de Assis criou instigante alegoria sobre a Proclamação da República e os sentimentos políticos do carioca, com relação àquele movimento militar, no dia em que ele aconteceu. No seu romance Esaú e Jacob, em metáforas sucessivas, criava o personagem Custódio, o seu estabelecimento comercial situado na Rua do Catete - uma confeitaria - e o objeto das preocupações desse comerciante, a tabuleta que anunciava o seu estabelecimento e por cujo nome nutria um especial enlevo: Confeitaria do Império.

A tabuleta estava um pouco desbotada, após tantos anos de uso e de tal forma que muitos clientes instaram para que ele mandasse reformá-la. Custódio a retira do frontispício, enviando-a a um artista por ele contratado, cuja oficina estava instalada à Rua da Assembléia. $\mathrm{O}$ artista deveria restaurar a tabuleta: era questão de reavivar suas letras e melhor destacar o já tradicional nome do estabelecimento; coisa rápida e econômica, que ele julgava fosse de grande eficácia (MACHADO de ASSIS, 1950; p..182/5; 233/6; 237).

Para surpresa de Custódio, o artista declarou não ser possível a restauração. Não era só uma questão de tintas, pois que a madeira estava rachada, velha, carunchada e carcomida: não suportaria nenhum restauro; era mister substituí-la por outra, nova. Muito a contragosto, Custódio autorizou a confecção da nova tabuleta, mas pedira urgência ao artista, porquanto desejava inaugura-la no domingo que se aproximava.

Ao despertar, na manhã da sexta-feira, 15 de novembro, teve notícias de que a República fora proclamada. $\mathrm{O}$ acontecimento tomou enorme vulto para o comerciante, pois que sua nova placa já estava pronta e, se a pendurasse, seria bem capaz de virem quebrarlhe as vitrinas. Mas, ele gostava tanto do antigo nome que, trocá-lo por Confeitaria da República, por exemplo, soava-lhe como uma traição àquele outro.

Wilson Martins, ao comentar as alegorias destes excertos, interpretou o personagem Custódio (aquele que custodia; o guardião), como sendo o próprio povo brasileiro; a confeitaria da Rua do Catete, era o próprio Brasil, do qual o povo é o guardião. Neste sentido, o nome que seria mais próprio àquela confeitaria, seria Confeitaria do Brasil, portanto, nem "do Império", nem "da República", mas do povo brasileiro (MARTINS, 1977; p.273).

Na visão machadiana, as instituições políticas nacionais estavam desgastadas; mas, não era questão trocar de regime, senão aperfeiçoar aquelas. Contudo, a classe política - que não era povo - assim não entendia: o artista, vale dizer, os políticos revolucionários ocupando o velho prédio da Rua da Assembléia, julgavam que as instituições políticas não suportavam nenhuma reforma, e a solução passava pela deposição da Monarquia e pela implantação da República. Representado em Custódio, e tal como ele, o povo carioca estava perplexo com os acontecimentos. Outros testemunhos do ato da Proclamação também convergem para a mesma visão, do perpassar de um sentimento de perplexidade. A célebre carta de Aristides Lobo, descrevendo os acontecimentos daquele 15 de novembro, também mostra o povo estupefato, como que expectante. E mais, ela justifica o receio que Machado de Assis colocou nos juízos de Custódio: o temor de represálias por parte dos militares, posto que o movimento não fora conduzido pelos civis (HOLANDA,1982; p. 119-120). 
De fato, tal sentimento já fora expresso na célebre carta de Aristides Lobo, sobre a Proclamação da República, na qual lemos: "Por ora a cor do governo é puramente militar e deverá ser assim. O fato foi deles, deles só, porque a colaboração de elemento civil foi quase nula. $\mathrm{O}$ povo assistiu àquilo bestializado, atônito, surpreso, sem conhecer o que significava." Também nas artes plásticas, Henrique Bernardelli o representou, em sua célebre tela sobre a Proclamação da República. Bernardelli representou nessa tela, uma hierarquia dos participantes da Proclamação: representou Deodoro, o comandante supremo, em primeiro plano, em atitude marcial, mas não fera, seu quepe na mão esquerda distendida, como que saudando o novo regime; Quintino Bocaiúva - e não viria a ser, ele, um dos "generais" civis da República? - equiparado a um militar, e no mesmo nível hierárquico que Benjamim Constant, ambos a cavalo e à direita do Proclamador; Aristídes Lobo, o líder civil, à esquerda e a pé; finalmente, atrás, o povo, massa expectante, amorfa e indistinta. ${ }^{1}$ Certamente, a autoridade de Aristides Lobo é incontestável para essas observações, porque foi testemunha ocular do ato da Proclamação, além de partícipe dos acontecimentos imediatamente decorrentes.

Outro aspecto dessa participação anódina do povo carioca nos acontecimentos do 15 de novembro refere-se ao momento em que Deodoro, comandando as tropas, deslocara-se para o Arsenal de Marinha, temeroso que estava quanto a eventuais reações das tropas navais, em vista do incidente havido poucos instantes antes, envolvendo o Barão de Ladário; o incidente fora notável ma historiografia da Proclamação da República, porque, representando o único gesto contrarrevoluçionário esboçado em apoio ao Imperador, em decorrência daquele movimento militar. De fato, o incidente se dera quando o Barão de Ladário, Almirante da Armada e, naquele momento, Ministro da Marinha, se dirigia ao Paço Imperial para uma reunião ministerial convocada para o exame da grave crise militar que se instalara. Parada a sua carruagem pelas tropas de Deodoro, e sendo por este informado do alcance do movimento e, portanto, recebendo voz de prisão, não titubeou o Ministro: com o risco da própria vida e com a convicção de que se encontrava diante de um motim contra o Imperador, sacara o seu revolver, atirando em Deodoro, mas errando o alvo; a reação da guarda de Deodoro, contudo, foi mais eficaz, o Ministro sendo baleado, embora não mortalmente, mas tombando naquele que se tornara o seu Campo de Honra. Foi este, o único sangue derramado contra a Proclamação da República!...sangue derramado pela fidelidade ao Imperador!

No Arsenal de Marinha, contudo, as tropas não encontraram resistências. Relata-nos Ernesto Senna que, os populares tendo adentrado os portões abertos do Arsenal, Deodoro pedira a Lopes Trovão que os retirassem dali, o que foi feito sem maiores problemas; contudo, ao saírem, alguns pediram a Lopes Trovão que lhes pagasse uma bebida, para saudarem a República, tendo este os conduzido a uma venda próxima, na rua $1^{\circ} \mathrm{de}$ março, esquina com Conselheiro Saraiva. A conta, de 40 mil-réis, acabou não sendo totalmente paga, porquanto consta que Lopes Trovão tinha apenas onze mil réis, no seu bolso; entregou-os ao vendeiro, e mais o seu relógio e respectiva corrente, como penhor do saldo; o comerciante recusou-o, dizendo que aquela seria a sua participação nas alegrias daquele dia (SENNA,1981: p. 106). Comentando este episódio, José Murilo de Carvalho conclui que aquele vendeiro, com o seu prejuízo, e sem o imaginar, tornava-se também em símbolo do povo sob o novo regime: "aquele que paga a conta" (CARVALHO, 1987: p.53). 


\section{Onde Estavam os Civis?}

Com o objetivo de se implantar a ditadura republicana no Brasil, nos moldes imaginados por Auguste Comte - ditadura perpétua, conduzida por um "notável" aos olhos da elite positivista ortodoxa - estes, buscaram influir nos destinos da República recém-implantada, ao menos procurando transformar a ditadura militarista, fundadora, em ditadura comteana. Não o lograram, contudo, impedidos pela ausência em que se haviam mantido, dos acontecimentos políticos anteriores àquele movimento militar, bem como à sua falta de poder político, mercê da reduzida massa de adeptos, realmente ortodoxos e ativistas; em verdade, também não puderam superar a atmosfera liberal, herdada do Império, que então já dominava a cena (CARDOSO,1933; p.309);

De fato, segundo Cruz Costa, eram 53 os positivistas ortodoxos existentes e inscritos, em 1889, na Igreja Positivista do Rio de Janeiro, e todos mais preocupados com a evolução do caso Laffitte e com a sua questão religiosa interna, desenvolvendo-se em Paris, que propriamente com a evolução política brasileira. A questão interna dos Positivistas brasileiros tomara o seu caninho definitivo com a publicação no Rio de Janeiro, em 18833 e para o público positivista brasileiro, do opúsculo intitulado Pour Notre Maître et Pour Notre Foi (assim mesmo, em francês, cuja tradução poderia ser: "Por nosso Mestre e Por Nossa Fé"), no qual Miguel Lemos declarava a ruptura da Igreja Positivista Brasileira com a orientação de Pierre Laffitte, cujo pensamento filosófico fora, por Miguel Lemos, considerado herético. Era um cisma interno, com o qual não concordara a maior parte dos Positivistas brasileiros. Portanto, será oportuno sabermos como se distribuíam esses Positivistas, no Brasil.

Nesse mesmo ano de 1883, Clovis Bevilácqua, no Recife, publicava o seu A Filosofia Positivista no Brasil, no qual assinalava que, ao contrário do Sudeste, onde predominava o Positivismo Ortodoxo, religioso, no Nordeste ele convergia para o Evolucionismo, o pensamento de Comte sendo substituído pelo de Spencer e Haeckel. No entanto, mais do que indicara Bevilacqua, também no Sudeste já não havia o predomínio do Positivismo Ortodoxo. J. C. de Oliveira Torres, no seu O positivismo no Brasil, (TORRES, 1943; p.181), classificava os positivistas brasileiros do fim do século XIX, em: Religiosos, Críticos e Orgânicos. Críticos e Orgânicos se diferenciavam apenas pelo matiz da sua práxis, posto que ambos eram conhecedores dos movimentos filosóficos e científicos do seu tempo, e tinham idéias próprias, evoluindo criticamente. Eram, portanto, os Evolucionistas, de Bevilacqua; nos Orgânicos, havia um espírito de busca da realização dos ideais comteanos, através da prática política; não se notava nestes, contudo, nenhum traço da ortodoxia religiosa daqueles do primeiro grupo. Homens como João Pinheiro, Júlio de Castilhos, Benjamim Constant e Silva Jardim, poderiam ser classificados como Orgânicos ; Sílvio Romero, Luiz Pereira Barreto e Tobias Barreto, seriam reconhecidos no grupo dos Críticos. No grupo dos Religiosos - também referidos como ortodoxos - encontramos Teixeira Mendes e Miguel Lemos; ainda neste grupo, encontraríamos tantos outros homens, civis e militares, alguns sem relevo próprio, mas produtores ou agentes de transformações sociais, todos componentes do reduzido grupo dos ortodoxos da religiosidade positivista, no Rio de Janeiro.

Não terá sido surpreendente, portanto, que, com a Proclamação da República, Teixeira Mendes e Miguel Lemos tenham, tardiamente, procurado influir no governo provisório, 
obtendo sucessos muito limitados, como o sabemos: não mais que o acatamento de sugestões para outros símbolos da República, além da Bandeira Nacional; sem dúvidas, teria havido sugestões, de ordem organizacional, muito provavelmente de natureza ditatoriais, próprias do pensamento político positivista ortodoxo, como podemos entender pelo discurso sobre o assunto, proferido por Rui Barbosa, no Senado da República, após a Proclamação: "Não faltaram à ditadura que fundou a República em 1889, conselhos e insistências de estirar por alguns anos, a sua duração".

Mas, retardatários à Proclamação da República não foram apenas os Positivistas Ortodoxos, que os Orgânicos, oriundos da Escola Militar, a fizeram: também à elite política constituindo os Republicanos, fração emergente do Partido Liberal e então pouco prestigiada politicamente; o novo regime veio surpreendê-los, porquanto, apesar das sucessivas crises políticas, nem mesmo a Questão Militar pudera despertá-los para a iminência daquele acontecimento inusitado. Apesar da intensa propaganda republicana circulando naquele momento histórico, esse movimento militar desembocando na Proclamação, fora preparado no sigilo dos quartéis, e neles permaneceu até a sua eclosão. A República já era uma realidade, quando - tal como os Positivistas Ortodoxos - os partidários do Partido Republicano despertaram. Bem o afirmara Rui Barbosa, ao comentar ter sido, ele próprio, um Republicano do dia 16 !

Contudo, a propaganda republicana havia minado a confiança da Inteligentsia brasileira no Império, como instituição política capaz de resolver as enormes demandas sociais do Brasil: havia a carência de educação e de saúde; havia a centralização das administrações provinciais, clamando por maiores liberdades administrativas e orçamentárias; enfim, havia toda uma expectativa de que um sistema republicano federativo viesse a suprir aquilo que o Império, em seus 67 anos de vida, não conseguira realizar. Por isso, a nova república, que se tornara expectante, era a República dos Bacharéis.

Acreditava-se que o movimento republicano traria consigo certa energia, capaz de remover os obstáculos ao desenvolvimento do País; capaz do espargimento de uma nova mentalidade, renovando os procedimentos administrativos e políticos, a condução da coisa pública, desenraizando a corrupção e aniquilando as negociatas. Eram disposições que careciam de uma cultura bem assentada, de uma disposição e visão de sociedade que se revelasse madura e decidida; era, enfim, disposições que não repercutiam na massa cidadã, porque, como já assinaláramos antes, cidadania ainda não havia, que bem as compreendessem e estimulassem. Contudo, a tendência dominante para a orientação constitucional foi a liberal federalista, conceitualmente elaborada e buscando expressar a idéia de que a organização política deveria estar centrada na solidariedade, na cooperação e na participação ativa e pacífica entre os Estados brasileiros, anteriormente as províncias, dotadas de escassas liberdades administrativas. Se as instituições eram aperfeiçoadas pouco a pouco, quanto à representatividade popular continuávamos a ser uma "democracia de notáveis" - para usar uma expressão de Helio Jaguaribe - onde o sentido de cidadania, aquela via por onde corre o respeito recíproco entre governantes e povo, ainda não fora despertado. (JAGUARIBE, 1985, p. 17). Aí está, certamente, uma das razões porque, em nossa história política, a presença decisiva da fração militar em permanentes atritos com o bacharelismo, venha sendo uma constante. 


\section{“Questão Religiosa" e Abolição da Escravidão: em que influíram?}

Sabemos que a "Questão Religiosa", que ocupou as preocupações políticas de Liberais e Conservadores moderados da segunda metade do século XIX, estava intrinsecamente ligada à questão da instituição do Padroado no Estado brasileiro, herança que fora do Estado Português, do qual, desde o nosso Primeiro Reinado, o herdáramos e o defendíamos ciosamente. Politicamente, a questão debatida na Câmara dos Deputados, girava em torno da permanência do Catolicismo como religião oficial do Estado brasileiro; a grande questão levantada, entre outros inconvenientes, referia-se ao extremado conservadorismo da hierarquia católica, que no momento trazia graves limitações às questões como o impedimento da adoção dos casamentos civis, atendendo aos anseios de crentes de outras religiões que não a católica. O problema era intensamente assinalado pelos Liberais, quando no poder, constrangidos pelas demandas da crescente imigração de crentes do protestantismo, essenciais ao desenvolvimento do País. Em oposição a tais demandas, se colocavam os bispos católicos, defendendo a manutenção da religião de Estado; contudo, paradoxalmente, se colocavam contra a instituição do Padroado, mas naquilo que respeitava às suas ingerências na administração eclesial católica, o que, no fundo, era uma prerrogativa do Estado para garantir a sua independência do poder eclesial. Por outro lado, havia a atitude de tolerância do episcopado, em relação à Maçonaria no Brasil, da qual inúmeros padres participavam. Porém, instruindo as posições clericais, o Papa Pio IX emitira, desde 1864, a Bula Syllabus, na qual condenava o pensamento Liberal nas sociedades modernas(Era a continuidade da grande luta contra o enciclopedismo); revigorava, assim, as atitudes ultraconservadoras da Igreja Católica; era o denominado ultramontanismo (o jesuitismo), revigorado pelo Concílio Vaticano I, de 1869-1870, no qual, sintomaticamente, a Infalibilidade papal fora erigida em dogma. Em tudo se formava um arcabouço propício às atitudes mais conservadoras dos prelados, o que, de fato, ocorreu com a "Questão Religiosa.."

Esta, impropriamente denominada "Questão Religiosa", no Segundo Reinado, iniciou-se envolvendo as relações da Igreja Católica com padres e outros fiéis, também maçons. Aqueles últimos, membros de diversas irmandades confessionais, às quais dois bispos aplicaram, indevidamente, sanções de dissolução civil, além de outras penas individuais, de sua competência, de excomunhão da Igreja para os seus dirigentes que não abjurassem da maçonaria. A impropriedade da denominação "Questão Religiosa" é devida ao fato de ela ter envolvido apenas dois bispos, em todo o território brasileiro: os ultramomtanos Bispo de Olinda, D. Vital Maria e o do Pará, D. Antonio de Macedo Costa; não houve quaisquer outras manifestações dos demais prelados brasileiros, que não fossem às questões da fé. As irmandades interditadas recorreram ao Conselho de Estado, reclamando - não sobre as questões da fé, como a excomunhão do culto - mas do Direito Constitucional (garantido pelo Instituto do Padroado), agora agredido, que era a dissolução daquelas Irmandades. A crise evoluiu para o julgamento dos dois bispos envolvidos, em crime contra a Constituição do Império; condenados a quatro anos de prisão, com trabalhos forçados, pena mais tarde comutada e, após, extinta por ato de anistia do Império. Portanto, essa foi uma questão pontual, que representou um novo capítulo da luta da Sé Romana contra o Padroado, luta agora reforçada pelo instrumento de um novo dogma, aquele da infalibilidade dos Papas. Quanto às conseqüências daquele ano de 1873, tão agitado politicamente, a dita "Questão Religiosa" somente veio a reforçar, nos meios Liberais, a absoluta necessidade 
de se estabelecer o Estado laico, como de pronto foi feito quando da Proclamação da República.

Alinhados ao pensamento historiográfico que minimiza aquela crise religiosa, bem como a "Abolição da Escravidão", pouco tenham influído na marcha dos acontecimentos que culminaram com a queda da Monarquia Coroada. Acreditamos, antes, que a idéia da República tenha sido preparada e anunciada, dia após dia, em conseqüência do que também fora criado o Partido Republicano, em 1870. De fato, não é outro o clima que percebemos retratado mo O Ateneu, romance impressionista, de Raul Pompéia, publicado em 1888. Tal como em Esaú e Jacob, de Machado de Assis, também podemos visualizar naquele novo romance, metáforas sucessivas levando a identificarmos naquele colégio situado no Rio de Janeiro, e destinado a filhos de famílias da elite social, e no seu diretor, Aristarco, com o Brasil de D. Pedro II. Sem pretendemos nos deter em análises sociológicas e na psicologia comportamental, que permitiriam ilações sobre a vida do autor como aluno interno de colégios cujos regimes tenham reforçado suas tendências íntimas, levando-o ao suicídio ainda na juventude, poderemos ressaltar que o incêndio encerrando aquela narrativa, tendo sido causado por um dos alunos, insatisfeito, e que destrói o patrimônio de Aristarco, que o assiste impotente, é uma metáfora final do que seria a próxima queda da monarquia, sob o incêndio republicano, para o próprio D. Pedro II.(MARTINS, 1996; p.299-301).

A República fora proclamada. O Estado republicano tornara-se laico. A "Questão Religiosa", necessariamente, não se transformara em passado; não se tornara mais que reminiscências, de quando em vez evocadas nos "serões" edificantes, no seio de famílias de fortes tradições católicas, ou de outros credos, ou ainda em umas poucas, também de fortes convicções agnósticas. Sem nos prendermos às correntes historiográficas que consideram a "Questão Religiosa" como um dos fatores que determinaram a queda da monarquia, também não poderemos ignorar que os sentimentos religiosos, católicos de origem, difusos em toda a população interiorana brasileira, eram aqueles mesmos que levaram a fortalecer as convicções de D. Vital Maria e de D. Antonio Macedo Costa, quanto à oportunidade das suas tão fervorosas quanto desastradas ações; aquelas, permaneceram tão intensas quanto antes: não se extinguem tradições pluricentenárias com revoluções sem povo!

De fato, a separação da Igreja e do Estado, realizada através do Decreto $n^{\circ} 119$ - A, de 07 de janeiro de 1890, não se deu sem resistências e traumatismos: a secularização do Estado foi contestada por prelados da Igreja Católica, que não se conformavam com as perdas dos seus privilégios junto ao Estado, embora não concordassem com as limitações às suas ações, que lhes eram impostas pelo mesmo Estado, através da lógica do Padroado; em dado momento, os apelos se tornaram patéticos, como no caso da carta reservada, enviada pelo Arcebispo da Bahia, D. Luís Antonio dos Santos, ao Marechal Deodoro da Fonseca, nos primeiros dias de dezembro de 1889; acenava-lhe, o prelado, com as responsabilidades que o Marechal assumira, naquele contexto revolucionário; exortava-o, o prelado, perante Deus, para que Deodoro cuidasse dos caminhos a que conduziria os maiores interesses da Igreja Católica no Brasil. Dizia a carta: "[...] pelas entranhas de Nosso Senhor Jesus Cristo, não consinta que façam da gloriosa espada de V. Excia. um instrumento da destruição da fé do povo brasileiro (...). Estamos ambos bem perto da eternidade, para temer à Deus, que nos há de julgar [...].”(MARTINS, 1996; p.318). 
Independentemente das convicções religiosas de Deodoro, a carta não surtiu efeito, mormente porque o assunto se encontrava nas mãos do Liberal e agnóstico Rui Barbosa, que já preparava a nova Constituição a ser votada em breve; também outros membros do governo provisório opinariam, mas todos eram impenitentes Positivistas Científicos, donde em nada lhes impressionar aquela argumentação do prelado. Por estarem dominados por aquelas ideologias, historicamente rejeitadas pela Sé Romana e, ainda, em permanente conflitos com elas, não atentaram para as entrelinhas daquela carta, que muito temia sobre os eventuais desrespeitos e, mesmo, até "(...)a destruição da fé do povo brasileiro." Desprezando qualquer entendimento a esse respeito, a República brasileira não revelou sensibilidade para julgar que, alguns movimentos com práticas exacerbadas de uma fé religiosa popular, cujas raízes mergulhavam no catolicismo medieval, não desejavam qualquer forma de restaurar a Monarquia, mas tão somente se assegurarem da liberdade do seu culto, que sentiam ameaçado pelas novas bases em que a República o situara. Estamos nos referindo, agora, aos fatos que originaram a Guerra de Canudos, aquele enorme genocídio contra o sertanejo baiano, que a jovem República cometeu: não se dando conta do que realmente fazia, acreditava estar combatendo uma reação monarquista restauradora.

\section{O Genocídio}

A povoação de Canudos era um lugarejo perdido no agreste baiano, tendo surgido ainda durante o século XVIII, nas terras de uma fazenda denominada Canudos. Situado no maciço de Cana Brava, como que formando o centro geométrico da grande curva que o Rio São Francisco percorre, delimitando os Estados da Bahia, Pernambuco e Alagoas; é irrigada pelo rio Vaza-Barris, que a atravessa no sentido Oeste-Leste; a cidade de Jereemoabo lhe fica situada a Leste, enquanto a localidade de Uauá lhe fica a Oeste; ao Sul, fica Monte Santo e a Noroeste, o importante centro comercial de Juazeiro; finalmente, a Nordeste, fica a atual Paulo Afonso. A povoação de Canudos passa a crescer, velozmente, após 1893, quando Antonio Conselheiro ali se estabeleceu. Este taumaturgo, nascido Antonio Vicente Mendes Maciel, em 13 de março de 1830, em Quixeramobim, no Ceará; originara-se de família com algumas posses, vivendo por mais de 25 anos naqueles sertões, entre sua cidade natal e a de Sobral, também no Ceará; dotado de alguma instrução, foi comerciante, professor primário e rábula, naquela região. Não sabemos se era vítima de alguma patologia psicótica, mas desde que fora abandonado pela sua mulher, passou a vagar por aqueles sertões, pregando para os sertanejos desvalidos, uma forma de sebastianismo, esperanças carismáticas de uma vida paradisíaca, após a morte, para os justos e sofredores sertanejos. Corria a fama de que fazia grandes milagres, o que o fazia ser considerado um "Santo Homem", um "Profeta", pelos sertanejos. Essa fama se consolidara durante a grande seca de 1877, quando sua atividade taumatúrgica contribuiu para aliviar os sofrimentos de tantos daqueles compatriotas abandonados à sua sorte pelas autoridades provinciais. Em 1893, encontrâmo-lo no arraial de Canudos onde, numa forma utópica de socialismo, passa a organizar o arraial sob a forma de comunidade religiosa, onde todos tinham o seu pedaço de terra para trabalhar, e o que produziam era revertido para toda a comunidade. Os tempos eram difíceis: a economia nordestina estava em crise, e os engenhos da região tornaram-se de "fogo morto"; a libertação dos escravos os lançou, desamparados, em um 
conflito direto com os latifúndios: estes, que antes, exploravam o trabalho dos escravos e, de qualquer forma que fosse, os vestiam e alimentavam, agora que se tornaram livres, os expulsavam, não mais assumindo a sua manutenção. Tais condições de vida a que eram lançados os ex-escravos, bem como outros flagelados pela grande seca, levava-os a uma vida errante e de crimes, para a própria sobrevivência. No Arraial de Canudos, Antonio Conselheiro oferecia àqueles deserdados sociais, uma alternativa digna de vida, em uma terra comunal; em nome de uma fé lastreada no catolicismo leigo, medievo, herança do Brasil Colônia, apresentando aspectos de religião familiar e patriarcal, de simplicidade ritual e "do consolo e das saudades de um paraíso um dia perdido". Eram estes, os sentimentos dominantes no sebastianismo presente no povo rude daqueles sertões (TAMBASCO, 2010; p.48-50). E de fato, a fama daquela comunidade se espalhava pelos sertões e, em 1896, o arraial de Canudos contava com uma população de cerca de 25.000 habitantes. Era, pois, em número de habitantes, o terceiro centro populacional da Bahia, apenas superado por Salvador e Feira de Santana.Não seria, pois, de admirar que o coronelismo sertanejo logo viesse a temer aquela nova manifestação social, que lhe subtraía a autoridade do mando político. Mas, não se tratava de um jaguncismo, porque eles não invadiam as propriedades alheias, roubando e matando; ao contrário, produzindo e vendendo seus produtos, ordeiramente, nas feiras regionais, não poderiam ser taxados de jagunços!. Contudo, em seu comportamento religioso, a Igreja católica não os via senão como um grupo herético, praticantes de toda a sorte de obscenidades; se não aceitavam o casamento civil, nem se conformavam com a separação entre Igreja e Estado...não havia alternativa: tratava-se de um grupo degenerado de monarquistas, ressentidos com a República, que se organizavam para a contra-revolução. Era mister destruí-los!

A oportunidade surgiu por ocasião em que o povo de Canudos decidira construir nova igreja no seu povoado; o madeiramento necessário foi encomendado e pago, no comércio de Juazeiro, mas não foi entregue; correu o boato que o Conselheiro invadiria a cidade, em represália; os próceres políticos locais obtiveram do Presidente da Bahia, Luis Viana, o envio de uma força policial, para conter os conselheristas. Em outubro de 1896, força composta por uma centena de homens, sob o comando de um tenente, fora enviada e, buscando o confronto, foi.completamente desbaratada, deixando armas e munições no terreno da luta; em janeiro de 1897, nova força mais numerosa, sob o comando de um major, tem o mesmo destino. Foi grande o reboliço entre os florianistas do governo republicano, para os quais a questão era a de uma iminente contra-revolução monarquista, para desestabilizar a República: o governo federal deveria assumir o combate aos conselheristas. Em março de 1897 era organizada e enviada a Canudos uma forte coluna, composta de 1.300 homens e quatro canhões Krupp; o comando dessa força fora entregue ao coronel Moreira César, cujas alcunhas, "gravata vermelha" e "corta-cabeças", obtidas nos confrontos rebeldes da Revolução Federalista, bem o indicavam pela ferocidade com a qual tratava os seus prisioneiros de guerra: era o comandante indicado para tratar daqueles "revoltosos" A expedição também foi desbaratada, morrendo o coronel Moreira César e, no mesmo dia, também morria o sub-comandante, coronel Tamarindo. Tal desastre desesperou os florianistas, que organizaram uma expedição de cerca de 5.000 soldados, em duas colunas comandadas por generais, sendo a expedição, fortemente armada e municiada, comandada também por um general, Artur Oscar Guimarães. Após várias escaramuças, com grandes 
perdas para o exército republicano, a 5 de outubro de 1897, o arraial caiu, quando, na expressão de Euclides da Cunha, [...] quando caíram os seus últimos defensores, que todos morreram. Eram quatro apenas: um velho, dois homens feitos e uma criança, na frente dos quais rugiam raivosamente cinco mil soldados.”( CUNHA, 1957; p.541).

O cadáver de Antonio Conselheiro, que morrera dias antes, foi exumado e transportado para Salvador, onde o seu crânio foi estudado, conforme preconizavam os princípios de uma antropologia lombrosiana. Em artigo publicado na Revista Brasileira, de 01 de novembro de 1897 e intitulado A loucura epidêmica de Canudos, Nina Rodrigues, al[em de não encontrar nenhuma anormalidade de conformação naquele crânio, não tergiversou ao atribuir a "psicose progressiva" de Antonio Conselheiro, como um reflexo das "condições sociológicas do meio em que se organizou." Fulminando os julgamentos florianistas sobre os conselheiristas, ele concluía: que o "monarquismo" de Antonio Conselheiro e seus seguidores era nada mais que o sentimento político correspondente à idade mental e sociológica daquela população sertaneja. Nina Rodrigues não completou suas análises com o desvelamento da vida miserável daqueles sertanejos, nem com o papel de líder religioso condutor de uma obra de dignificação social daquele povo, o que seria mostrado por Euclides da Cunha, no seu monumento da nacionalidade, que foi $O s$ Sertões.

Ser cidadão é ter direitos civis, o que quer dizer, entre outras coisas, a ter direitos à vida, à liberdade, à propriedade e à igualdade perante a Lei. Tudo isto foi, pela República florianista, negado ao povo de Canudos. Aquele episódio foi, por isto tudo, um terrível e lamentável genocídio. 


\section{Notas}

1 A respeito do imaginário na República, ver: CARVALHO, J. M. de. A formação das almas. O imaginário da República no Brasil. São Paulo: Cia das Letras, 1997; em particular, sobre o quadro de Bernardelli, ver às p.51 e 97. Ver, também: SENNA, Ernesto. Deodoro: subsídios para a História.. Brasília: EDUNB, 1981, p.143. Este autor apresenta o testemunho de Sampaio Ferraz, que assistiu todo o movimento das tropas diante do Quartel General e registrou, ali, a presença de Quintino Bocaiúva, à cavalo, mas não, junto a Benjamin Constant.

\section{Referências}

CARDOSO, Vicente Licínio (1933). À margem da História do Brasil. São Paulo: Nacional.

CARVALHO, J. Murilo de. (1997) A formação das almas. O imaginário da República no Brasil. São Paulo: Cia das Letras.

CARVALHO, J. Murilo de. Os bestializados. O Rio de Janeiro e a República que não foi. São Paulo: Cia das Letras, 1987.

CUNHA, Euclides da. (1957) Os Sertões (25a . ed.). Rio de Janeiro: Livro Francisco Alves, 1957.

HOLANDA, Sérgio Buarque de. Raizes do Brasil. (21 ${ }^{\text {a }}$. ed). Rio de Janeiro: J. Olympio, 1982.

JAGUARIBE, Hélio. Raizes do Brasil e a transição para a sociedade de massas. In: MASCARENHAS, Sérgio (org.). Raizes e perspectivas do Brasil. Campinas: Papirus/ UNICAMP, 1985.

MACHADO DE ASSIS, J.M. Esaú e Jacob. Rio de Janeiro: W.M. Jackson, 1950;

MASCARENHAS, Sérgio (org.). Raízes e perspectivas do Brasil. Campinas: Papirus/ Unicamp, 1985.

MARTINS, Wilson. História da inteligência brasileira (2a .ed). São Paulo: EDUSP, vol. III (1977).

MARTINS, Wilson. História da inteligência brasileira (2a . ed). São Paulo: L.A.Queiroz, Vol. IV (1996).

PINSKY, Jaime \& PINSKT, Catla Bassanezi (Orgs.). História da Cidadania. São Paulo: Contexto, 1993.

SENNA, Ernesto. Deodoro: subsídios para a História (2ª ed). Brasília: Edunb, 1981.

TAMBASCO, J. C. Vargens. A Serra e o Santuário. Nossa Senhora da Piedade do Caeté: Uma herança setecentista das minas do ouro. Vassouras: Edição do Autor, 2010.

TORRES, J. C. de Oliveira. O Positivismo no Brasil. Petrópolis: Vozes, 1943. 